\title{
The Essence of E-education: Rational Thinking about Flipped Classroom Jiling $\mathrm{He}^{1 \mathrm{a}}$, Zijing Wang ${ }^{1 \mathrm{~b}}$, Shipin Chen ${ }^{1 \mathrm{c}}$ \\ ${ }^{1}$ School of education, China West Normal University, Nanchong, Sichuan,637009, China

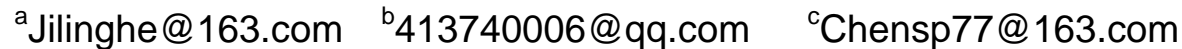

Keywords: flipped classroom; student-centered; zone of proximal development

\begin{abstract}
To solve the problem whether Flipped Classroom is suitable for the Chinese primary schools, this paper illustrates the concept and main idea of Flipped Classroom, then argues that there is great challenge to deeply carry out the Flipped Classroom in the Chinese primary schools, especially in developing the high quality education resources, building the online education platform and guaranteeing the learning quality of students before class. So this paper points out the essence of e-education, which includes exerting students' principal role to arouse their active learning, playing a guiding role of teachers to let students break through the cognitive obstacle and appropriately facilitating student's development by utilizing the zone of proximal development. Based on these mentioned points, it suggests that Chinese primary schools should apply to laws of education to explore the new educational reform supported by IT.
\end{abstract}

\section{INTRODUCTION}

Facing globally prevalent Flipped classroom, lots of Chinese primary schools are striving to get involved in this education reform, trying to explore the new e-education and seek more efficient ways to instruction. However, During the process of trying to innovate the new teaching method, the majority of primary schools should rationally understand the essence Flipped Classroom and its application conditions, and explore the suitable e-education according to the local conditions.

\section{THE CONCEPT AND CONTENT OF FLIPPED CLASSROOM}

As a new paradigm of reforming classroom teaching method, Flipped Classroom can be substantially defined as Flipped learning. Some scholars believe that flipped learning is a study method that students perform self-directed learning before class relying on teaching materials, especially teaching videos, and finish exercises, ask questions, or carry out project practice, application experiments, cooperative study, profound discussion with teachers' help in class. [1] In essence, Flipped Classroom inverts the order of traditional classroom teaching supported by information technology. During the traditional classroom teaching, teachers teach in class while students study after class. During the Flipped Classroom, teachers record the teaching videos, and put them in the online teaching platform for students to watch on-line or download before class. Then teachers solve the questions of students occurred in the learning process before class, deepen students' understanding of teaching content, and improve students' knowledge migration through discussion and communication in class. The teaching method of Flipped Classroom seemingly just adjusts the process of preparation before class, study in class, and review after class. However, it incorporates the core idea of education reform, which shows on two sides. On the one side, Flipped Classroom is characterized as student-centered, indicating that students are the principal part of study activity. Flipped Classroom enables students to actively participate in learning by liberating them from traditional passive learning. On the other side, this teaching method exemplifies the idea of "learning before teaching". The purpose of teaching is to promote students' learning. After students acquire new knowledge by watching teaching videos before class, teachers mainly solve student's questions occurred in the process of learning, and help students gain a deeper understanding of knowledge, and upgrade the capability of knowledge migration in class. 


\section{CHALLENGES OF FLIPPED CLASSROOM IN CHINESE PRIMARY SCHOOLS}

As a new teaching paradigm, Flipped Classroom reforms traditional classroom teaching method. In recent years, lots of primary schools in China have been passionately pursuing the Flipped Classroom. They believe that Flipped Classroom symbolizes the prospect of future e-education, and all try to carry out the reform of Flipped Classroom. Although the enthusiasm of education reform and creation is understandable, the actual action requires rational thinking. From practical aspect, Chinese primary schools confront some significant challenges while they plan to carry out the Flipped Classroom. Whether Flipped Classroom is appropriate for primary schools needs some farther trials. Flipped Classroom in Chinese primary schools needs to overcome the following difficulties. ${ }^{[2]}$

First, primary schools need to acquire the capability of developing high quality education resources. Theoretically, the development of modern information technology provides primary schools with feasibility of developing high quality digital educational resources. Genuinely, however, lots of primary schools are constrained by all kinds of factors like teacher resources, financial ability, and technology, and they don't have to qualify for developing digital educational resources. In other words, the teaching video is prerequisite to carrying out Flipped Classroom. Involved with various primary subjects, to record the teaching video is actually a huge project. Primary schools should select outstanding teachers and train them, develop the teaching video collaborated with high-level technique teams. On the other hand, the development of basic education in China is not balanced so far. Except for some urban primary schools that are eligible for the prerequisite, many rural schools, especially schools in the west of China, are barely able to produce the teaching videos with their financial ability and teacher resources. So the development of high quality digital teaching resources becomes one of the challenges of the primary school to carry out the flipped classroom.

Second, primary schools need to acquire the online teaching platform. Other than the capability of developing high quality digital educational resources, the online teaching platform is also required to store massive teaching videos which students could download or watch online. For the present, basic educational informationization in China is trying to realize "three links, two platforms", which includes broadband network school link, classes in communication quality resources, e-learning space for all, public service platform for educational resources and public service platform for educational management. Nonetheless, lots of primary schools, especially those in the rural and remote areas, have not built “three links, two platforms" and hence couldn't provide the online teaching platform for the implementation of Flipped Classroom.

Third, it's hard to guarantee good quality of primary school students' study before class. Even if primary schools can afford to record a large amount of shareable teaching videos and put them in the online teaching platform, would that exactly lead to students' study before class? On the one hand, students' families are required to access to watching teaching videos by either the Internet or DVDs which is not reachable for each family. On the other hand, many primary school students are too young to study on their own and strictly control themselves. Without parents' help, these students can hardly accomplish their former study tasks before class in Flipped Classroom and thus can't study efficiently. In addition, students must have a more difficult time taking several different courses before class, and it's hard to tell whether they can go through study of all those subjects in time. Since lots of primary school students at the tender age lack sufficient time for learning before class and the capability of studying independently, learning quality before class in Flipped Classroom can't be guaranteed. As a result, teachers have to spend more time making up for students' inefficiency and hence the efficiency of Flipped Classroom would be reduced.

\section{THE ESSENCE OF INNOVATION OF E-EDUCATION}

In recent twenty years, China has focused on boosting basic educational informationization and thus promoting the reformation and development of basic education. Apparently, classroom teaching is the mainstream in basic education. To truly promote the creation and reformation of 
basic education, educational informationization must go deep into classroom teaching reform. Since basic education informationization occurred, classroom teaching method has constantly improved and changed from computer aided instruction to computer aided learning, from face to face teaching to eLearning, from eLearning to blended learning, from lecture teaching to inquiry learning and so on. No matter how teaching method has reformed, the main purpose is to improve the efficiency of teaching and the quality of talent training. To avoid blindly following the trend of education reform, all primary schools must recognize the essence of classroom teaching reform and promote the efficiency of teaching based on the following points.

First, instruction must fully exert students' principal part and facilitate students' active participation. Interest is the best teacher who leads students to explore undeveloped fields. The new curriculum reform has transformed the traditional indoctrinatory teaching method into significant student-centered learning with the teachers' guide. Actually, guiding by Constructivism, the reformation is supposed to exert students' principal part in learning process while teachers play a leading role in teaching. In short, good classroom teaching method is closely linked to students' active participation. Students develop their mental through observation, thinking, or action when they take part in the activity of teaching. According to Dale's cone of experience, learning is the increase in experience, whether it is by observation or by action, whether it is direct experience or indirect experience. Therefore, students' active participation can help to accumulate experience and make learning take place. As for students, any teaching process in which no students' active participation takes place could be indoctrinatory teaching. It's improbable that students who passively study could achieve good results. Suggested in the new curriculum reform, a series of new teaching method, such as tasks-based learning, problem-based learning, inquire learning based on resources, is all about exerting students' principal part, and motivating students to learn actively by means of negotiation and communication and realizing the significance and construction of knowledge.

Second, teacher play a guiding role in teaching process to break through the cognition obstacle of students' development. In the process of teaching, what the students are engaged in is the knowledge and skills in unknown fields, so confusion and questions are inevitable in the process of learning. Exactly, these cognitive conflicts are the key to improve students' learning. When the students confront cognitive conflicts, teachers should provide assistance to students, and improve the development of students. So teachers' guiding is extremely emphasized in the new teaching method suggested by new curriculum reform. Like a lighthouse, teachers should be responsible for providing students' active learning with directions, help and guide students when they deviate from the main course and meet challenges.

Third, instruction must utilize zone of proximal development to improve students' development. Students' progress shows regular patterns and cannot be made excessively and rapidly. According to the zone of proximal development theory, teachers should be aware of students' initial knowledge background and cognitive level in the process of teaching. Based on students' conditions, teachers reasonably arrange curriculum schedule and the pace of teaching, creating a virtuous cycle of development by letting students reach their study goals independently. In the era of information explosion, teaching can't stick to memorizing, comprehending, and preliminary application. Instead, it should evolve to lead students to high-level thinking such as analyzing, synthesizing, and creating, develop their abilities to discover, analyze, and solve problem, and thus reach the goal of developing students' innovative thinking and practical abilities.

To sum up, classroom teaching is the mainstream in basic education. Primary schools should concentrate on classroom teaching with extracurricular activities as supplement, making full use of classroom teaching to best promote the quality, efficiency, and benefit of teaching. Flipped Classroom is a informationized teaching method popularized abroad. In our country, however, it doesn't necessarily suit every primary school under the imperfect condition of informationization. While exploring classroom teaching reform, primary schools should follow the rule of cognitive development of students with basic education informationization as a reference and would eventually seek out the informationized teaching method that can best fit their own school under 
with local conditions. High efficiency classroom teaching method, no matter how it would change, is always tied to three fundamental principles, which includes exerting students' principal part to arouse students' active learning, playing a guiding role of teachers to let students break through the cognitive obstacle and appropriately facilitating student's development by utilizing the zone of proximal development.

\section{EXPECTATION FOR E-EDUCATION IN PROMARY SCHOOLS}

The establishment of "three links, two platforms" will create an ideal e-education circumstance for primary schools developing e-education, which can solve the problem that primary schools lack for online teaching platform and high quality education resources. As to build and share of high quality resources, the country can select well qualified teachers to develop educational resources by centralized construction or broadly gathering from primary school. In addition, cloud computing technique offers ideal technological support to future primary schools' digitalized campus. With the establishment of digitalized campus based on cloud computing through internet, both teachers and students would access high quality education resources on the public service platform of education resources any time and every school would be definitely high-end and prominent. ${ }^{[3]}$ E-education service mainly focuses on solving the instructional problems. Service engineers will help teachers efficiently deal with technical problems in the process of teaching. ${ }^{[4]}$ On this basis, Flipped Classroom should be tested on high-level grades (more than grades three) in primary schools to be more reliable and matured. As basic education informationization has become extremely influential, e-education in basic education will reach normality. Lots of schools are supposed to grasp the essence of e-education innovation and keep exploring in practice. Besides Flipped Classroom, there must be more advanced e-education models in the future.

\section{ACKNOWLEDGMENT}

It is supported by the National Society Science Fund project "research on the structure, process and mechanism of university informationization construction (No. 12BGL097) ". Shipin Chen is the Corresponding author.

\section{References}

[1] Qing Weiwei. Flipped learning: the new paradigm of classroom teaching reform. E-education Research. August 2013, pp.84-90 (In Chinese)

[2]He Kekang. The essence and future of flipped classroom. E-education Research. July 2014, pp.5-16 (In Chinese)

[3] Shang Junjie, Jiang Yu. Cloud-computing and digital campus. Information Technology Education in School. January 2015, pp.27-30 (In Chinese)

[4] Zhou Kai. Improving the teachers' ICT competence by using internet service. Information Technology Education in School. February 2015, pp.24-26 (In Chinese) 